\title{
The Promise of Dynamic Systems Approaches for an Integrated Account of Human Development
}

\author{
Marc D. Lewis
}

\begin{abstract}
After decades of theoretical fragmentation and insularity, a converging explanatory framework based on general scientific principles is an important goal for developmental psychology. Dynamic systems approaches may provide such a framework, using principles of self-organization to explain how novel forms emerge without predetermination and become increasingly complex with development. New trends in traditional theoretical families emphasize systemic, emergent processes, and these can now be explicated with principles of selforganization that apply to all natural systems. Self-organization thus provides a single explanation for the multiple facets of development, integrating diverse developmental viewpoints within a larger scientific perspective.
\end{abstract}

\section{INTRODUCTION}

The proliferation of incompatible theories and theoretical families is as daunting to developmentalists as to the educators and practitioners we are trying to reach. This is especially problematic because most theoretical camps do not share obvious conceptual currency with each other or with the sciences at large, and this makes their incompatibilities hard to resolve. A scientific discipline can profit from radically different claims and vigorously competing theories, but it needs some body of shared insights or a general framework for reconciling different positions. Moreover, the theoretical Tower of Babel characterizing developmental psychology encourages the divorce of empirical investigation from theory. Most of the empirical studies reported in developmental journals have little to say about theoretical implications, perhaps because those implications are too difficult to sort out. The combination of theoretical fragmentation, conceptual insularity, and empirical arbitrariness in developmental psychology can at best hamper progress and at worst provide an illusion of progress. Many would agree that a converging explanatory framework, based on general scientific principles, is a vital goal for the next generation of developmental theorizing.

In the last few years, the dynamic systems (DS) approach to development has sought to fill this role. Dynamic systems theorists claim that all developmental outcomes can be explained as the spontaneous emergence of coherent, higher-order forms through recursive interactions among simpler components. This process is called self-organization, and it accounts for growth and novelty throughout the natural world, from organisms to societies to ecosystems to the biosphere itself. According to principles of self-organization, these entities achieve their patterned structure without prespecification by internal rules or determi- nation by their environments, and human development is just one exemplar of a universal tendency toward higher-order coherence.

Motor development has now been quite thoroughly examined from a DS perspective. Cognitive development is following suit, and papers on emotional and personality development, temperament, and developmental psychopathology are beginning to incorporate DS principles as well. Lower-level constituents and higher-order forms are specified differently in each of these domains. In motor development, recurring interactions among muscular and perceptual activities are seen as giving rise to patterns of coordination that underlie skills such as reaching and walking (Thelen \& Smith, 1994). In emotional development, it is hypothesized that interpretations and associations couple recursively with basic emotions to fashion coherent personality dispositions (Izard, Ackerman, Schoff, \& Fine, in press; Lewis, 1995). Temperament is thought to consolidate from repeated interactions among motivational and regulatory systems (Derryberry \& Rothbart, 1997), and cognitive development can be seen to emerge from the coordination of attentional, conceptual, and linguistic constituents (Smith, 1995; van Geert, 1994). DS theorists argue that even such diverse phenomena as these can be modeled using a single explanatory framework based on principles of self-organization.

Many developmentalists are intrigued by the DS approach but they do not fully understand it, and their confusion is exacerbated by the new and competing terminologies, conceptual ambiguities, and methodological disagreements that pervade DS writings. The present essay is intended to explicate the DS approach as broadly as possible, to demonstrate its uni-

(C) 2000 by the Society for Research in Child Development, Inc. All rights reserved. 0009-3920/2000/7101-0005 
fying potential, and to dispel some of the accompanying confusion. In the first part of the essay, I briefly review the state of fragmentation in the present metatheoretical landscape and highlight trends toward a new emphasis on systems thinking and developmental emergence. I then suggest how the DS approach can integrate these trends in a scientifically grounded framework. In the final part, I examine the ambiguities in DS writings and suggest directions for clarifying them. I argue that these ambiguities should not be confused with dissonance in the field at large. They are signs of growth rather than fragmentation, and they suggest a conceptual shift that can unify and revitalize our discipline.

\section{THE PRESENT METATHEORETICAL LANDSCAPE}

Traditional theoretical families have each contributed unique and crucial insights to the study of development. To greatly oversimplify, mechanistic theories have been valuable for modeling the rule-based regularities in development, especially those that are common to human and nonhuman information-processing. Organismic theories have been successful at capturing the wholeness of developmental order, including normative progressions and their qualitative reorganizations (e.g., stage shifts). Contextualist approaches have investigated the effects of interaction and goodnessof-fit between children and their environments. Learning theories have established the importance of knowledge organization in the world and its transfer from the world to the child. Nativist theories, in contrast, have shown how developmental acquisitions rely on the specialized cognitive and emotional propensities of our species. Finally, constructivist approaches have resolved some of the tension between nativism and learning by positing the assembly of internal structures through the child's active engagement with the world.

Yet the widely divergent perspectives of these theoretical families produce very different accounts of development. This divergence suggests that each perspective is limited, incomplete, or specialized, and that some sort of integration or synthesis is necessary to get a comprehensive picture of human development. Is such an integration possible?

Mechanistic explanations have had an enormous impact on developmental theory, as exemplified by information-processing models of skill and strategy acquisition (e.g., Siegler \& Jenkins, 1989). However, mechanistic explanations are completely incompatible with the organismic metaphor, which emphasizes the wholeness of a developmental process that cannot be reduced to its parts (Overton, 1984). Organismic theories, in turn, imply a centrally directed, unfolding continuity that is difficult to reconcile with contextualist arguments for environmental causation, sudden interruptions, and individual differences in timing (Lerner, 1995; M. Lewis, 1997; Ryan, Kuhl, \& Deci, 1997). Moreover, organicism seeks to explain the origins of developmental forms, whereas contextualism is concerned with the processes that modify them. Thus, neither mechanistic, organismic, nor contextual theories can fully explain development on their own, and it may be impossible to integrate them because they are incommensurable.

Similarly, the nativist and learning camps, each highly productive and influential, have no common language to discuss developmental causation (see Molenaar, 1986). For nativism, the structure of the nervous system prescribes the structure of development. For learning approaches, orderliness is already present in the world, recorded by the mind, and mirrored by developmental acquisitions. Constructivist theories have attempted to resolve this contradiction, explaining developmental order as the building of new assemblies from preexisting constituents. Yet for some constructivists these constituents are supplied by learning (e.g, Case, 1985; Fischer, 1980), and for others they are innate (e.g., Karmiloff-Smith, 1992); there still seems to be no comfortable middle ground. Moreover, constructivist assumptions of universal teleology and progress are difficult to square with the diverse outcomes of individual developmental contexts (Keating, 1990). Thus, nativist and learning explanations remain incompatible, even through the lens of constructivism, and constructivist formulas for progress ignore the diversity that is central to contextualist accounts.

\section{MOVING TOWARD EMERGENCE}

It appears that the members of each of these theoretical traditions owe their family resemblance to a particular metaphor, emphasis, or viewpoint, not a scientific explanation (e.g., Overton, 1984). This does not mean that they are not proper scientific theories. But it does mean that they end up insulated from each other if not completely incompatible. Mechanistic theories compare developing humans to machines, organismic theories compare them to plants, and constructivist theories compare them to builders with a universal tool kit. Nativist theories emphasize biological causation whereas learning theories emphasize environmental causation. Each of these metatheories explains a distinctive aspect of development rather than accounting for development as a whole. Yet the incommensurate metaphors or perspectives from which 
they derive make them very difficult to calibrate with each other. Thus, no integrated account can be fashioned by combining them.

These and other frustrations have led some investigators from each of these traditions to a similar resolution-viewing emergence as a general principle for explaining developmental change. The word emergence has a special, even radical, significance in scientific explanation: it refers to the cominginto-existence of new forms or properties through ongoing processes intrinsic to the system itself. Emergence is not just another metaphor. It does not suggest a comparison with something else. Rather, it is a general principle that can be applied to understanding change and novelty in all natural systems and it is the key principle underlying self-organization. But before exploring this idea in more depth, it is important to see how models of emergence and self-organization have themselves emerged within each of the major theoretical traditions in developmental psychology.

Mechanistic accounts have largely shifted from traditional information-processing to connectionist models, in which developmental patterns emerge (spontaneously) without instruction or rules (e.g., Shultz, 1998). The limitations of organismic models have led Chapman (1991), Ryan, Kuhl, and Deci (1997), Sameroff (1995), and others to embrace a systemic perspective highlighting adaptive self-organization. Contextualist researchers have achieved flexibility through systemic thinking (Lerner, 1995; M. Lewis, 1997) and increased explanatory power by modeling the emergence of unique outcomes from indeterminate beginnings (Keating, 1990). The incompatibility of nativism and learning led Molenaar (1986) to propose self-organization as the real source of developmental novelty. Ten years later, this position has become elaborated and extended with reference to connectionist networks and human biology (Elman et al., 1996). In the constructivist camp, neo-Piagetians have looked to dynamic systems principles to model growth profiles that arise from recursion rather than construction (Case et al., 1996; Rose \& Fischer, 1998). This trend captures systemic ideas from earlier neo-Piagetian writings (Pascual-Leone \& Goodman, 1979) and recapitulates Piaget's insistence on spontaneous integration through equilibration, a process that taps the essence of self-organization (Chapman, 1991). Similarly, the organizational approach to socioemotional development, based largely on constructivist assumptions, has begun to make use of dynamic systems ideas (e.g., Sroufe, 1995).

These investigators have come to see developmental change as indeterminate as well as principled, self- augmenting as well as unfolding, and creative as well as responsive. In other words, they have begun to characterize development as emergence rather than growth, learning, or construction. The visionary theorists from earlier in the century, Piaget and Baldwin, understood the importance of emergent form (Chapman, 1991; Valsiner, 1995; van Geert, 1998), but the constructs and methods available to them did not permit the full explication of this insight. We are now ready to get specific.

The other sciences have provided us with models and mechanisms for studying emergence as selforganization in a complex dynamic system. Computer science has shown us how knowledge states selforganize in densely connected networks (Shultz, 1998). Biological approaches demonstrate how evolution, perception, and communication converge in a selforganizing, embodied mind (Varela, Thompson, \& Rosch, 1991). Neuroscientists can now watch stimulus events trigger pattern formation in self-organizing brains (Freeman, 1995). And mathematics offers formal tools for modeling change with nonlinear dynamics (Newell \& Molenaar, 1998). These advances tap a new understanding of order and novelty that is rapidly consolidating in the natural sciences. A scientific account of human development must also take them seriously.

\section{SELF-ORGANIZATION: TOWARD AN INTEGRATED ACCOUNT OF DEVELOPMENT}

In the natural sciences, self-organization denotes a conceptual framework for looking at the spontaneous emergence of order in physical, chemical, and biological systems. When these systems are far from equilibrium (and this is inevitable in biological systems), the rapid flow of energy links their elements into orderly arrangements (Prigogine \& Stengers, 1984). At the same time, such links give rise to positive feedback cycles which amplify local patterns into macroscopic regimes. Some order is unavoidably lost through entropy, but, contrary to the second law of thermodynamics, the overall organization of the system increases. Hence: self-organization. This insight is the basis for different theories that attempt to explain emergent order in various fields (Capra, 1996). No single theory of self-organization has been established in the field of human development (though Thelen \& Smith, 1994 , have come closest). However, principles of selforganization seem able to bridge many of the contradictions between traditional approaches, incorporate their insights, and suggest the broad outlines of an integrated account.

First, self-organizing systems permit true novelty: new forms spontaneously appear with time, entrain- 
ing the interactions of the elements that give rise to them. For example, Thelen and her colleagues (e.g., Thelen \& Smith, 1994) look at the emergence of walking in infant development. The coordination of many systems of muscles and perceptual processes gives rise to this coherent yet advanced form, without instruction by parents and without any innate motor program. At the same time, this pattern of coordination is recruited in the service of a unique function, and this maintains and reinforces its links over time. New macroscopic forms and new patterns of microscopic coordination cause one another in self-organizing processes (Haken, 1987), providing nature with a marvelous means for creating what was not previously there. Thus, structure does not have to be imported into a system from outside, as presumed by learning approaches, nor preordained from within, as presumed by nativist approaches. Structure is emergent.

Second, self-organizing systems become more complex. Their increasing orderliness means that they can maintain a more sophisticated arrangement of coordinated parts or processes, and they do so spontaneously in the service of adaptive functions. From the DS perspective, it is no accident that increasingly complex developmental forms are also increasingly functional, because new functions are precisely what are needed to maintain new coordinations. For example, the interpersonal modes that emerge in communicative development become more complex with age. After infancy they begin to incorporate gestural, verbal, and role-related actions in elaborate communicative rituals or frames. These frames are maintained simply by the "consensus" of two intentional participants, but they also serve increasingly comprehensive goals with development (Fogel, 1993). Thus, complexity does not have to be constructed from preexisting forms nor follow a universal direction. Coordination is free of constructivism.

Third, global reorganizations occur at phase transitions, points of instability and turbulence where old patterns break down and new ones appear. Phase transitions are both global and abrupt, indicating that new configurations require the cooperation of all system components; they cannot remain at in-between states of partial reorganization. This idea has two ramifications: (1) New levels of complexity appear discontinuously, as exemplified by developmental stages. In empirical work, van Geert (1994) and van der Maas and Molenaar (1992) have shown that new cognitive and linguistic abilities increase abruptly from very low to very high levels, passing through a period of extreme variability while doing so. (2) Development is strongly influenced by small effects at these junctures, such that new forms are not determined by their precursors. This is most evident in personality transitions, for example in early adolescence or early adulthood, when emotionally loaded life events can trigger massive reorganizations of personality and identity (Lewis \& Douglas, 1998; Magai \& Nusbaum, 1996). Taken together, the properties of phase transitions ensure that novelty is progressive, discrete, idiosyncratic, and unpredictable-a synthesis that transcends mechanistic and organismic accounts.

Finally, self-organizing systems are both intrinsically sensitive and intrinsically stable. They are exquisitely sensitive to aspects of their environments because of their propensity for feedback and coupling with other systems. For example, infants will shift between walking and crawling in response to small changes in the texture of the ground, as mediated by feedback between muscle movements and the (sometimes dramatic) effects of the ground on the infant (Thelen \& Smith, 1994). Yet the internal closure of developing systems is actively self-perpetuating, partly because recurrent patterns of coordination increase the likelihood of their own recurrence. This is true of course in learning to walk, but it can also be seen in the resilience of individual coping strategies despite environmental impediments and novel challenges (Lewis \& Douglas, 1998). Such a dual orientation allows for the context-sensitivity proposed by contextualists and the context-insensitivity highlighted by nativist and organismic approaches.

Thus, a general framework based on principles of self-organization seems to bridge the limitations of traditional theoretical families and incorporate many diverse aspects of development in a unitary scheme. This scheme accounts for the creation of order from intrinsic processes, the increase in complexity over time, the emergence of true novelty within developing systems, transition points that permit both structural advances and individual diversification, and the capacity for self-correcting stability as well as sensitive adaptation to the environment. Moreover, this is not just a descriptive scheme; it is one that provides a coherent explanation for development. Emergent order necessarily results from spontaneous coordination entrained with macroscopic form and function. This principle necessarily yields qualitative changes as new organizations entrain the interactions of lower-order elements. These qualitative changes are necessarily discontinuous and sensitive to small effects because movement from one orderly regime to another necessarily spans a phase of relative disorder. Selforganization thus provides a single explanation for the multiple facets of development, and this explanation may serve as a general framework that can po- 
tentially unify our discipline. The fact that this is a special case of an even more general framework, one that explicates the emergence of order in physics, chemistry, biology, ecology, and cosmology, permits developmental science to take its place in the family of sciences, sharing common conceptual foundations yet pursuing its own unique questions.

If the DS theoretical family can potentially offer an integrated account of development, then it must have a coherent conceptual agenda of its own. Yet DS writings have been fraught with disparities in terminology, conceptual contradictions, dissimilar methodological approaches, and arguments about theory versus metaphor. These points of difference have created some confusion for mainstream developmentalists as well as DS researchers themselves. The next section examines five points of confusion and outlines directions for clarifying them. I suggest that, underlying these superficial differences, self-organization constitutes an integral idea, shared by DS developmentalists as well as other scientists. Yet this idea is still emerging from a turbulent phase transition in theory development, and it is only now beginning to stabilize.

\section{CONFUSION AND CLARIFICATION IN DYNAMIC SYSTEMS APPROACHES}

1. What are we talking about? Dynamic systems theory, nonlinear dynamics, chaos, complexity, and self-organization denote different but overlapping topics in science and mathematics. But developmentalists, and psychologists in general, skate across them indiscriminately, and this is bound to invite confusion. For example, some psychologists include all contemporary systems accounts under chaos theory (e.g., Abraham \& Gilgen, 1995), but others contend that chaos is completely outside the range of most psychological research and theory (Kelso, 1995). Even within a given nomenclature there is little definitional consensus. Does dynamic systems refer to a theory (Thelen \& Smith, 1994), an approach (Fogel, 1993), or a mathematical technique (van Geert, 1998)? Does selforganization describe momentary change, developmental emergence, or both (Thelen \& Ulrich, 1991)? If the experts are this confused about terminology and conceptualization, why should anyone listen?

It is true that variance in terms, definitions, and applications of DS concepts confuses both DS researchers and their audience. But there is little variance in the underlying view of development to which these terms apply. Terminological imprecision and ambiguity are unavoidable given the novelty of DS ideas in developmental psychology (Lewis \& Granic, 1999). Any new metaperspective is bound to exhibit fluctu- ating semantics for a while. Terminological and semantic discrepancies concerning nonlinearity, complexity, and self-organization can be found in the natural sciences as well. This general semantic turbulence suggests a reorganization or paradigm shift across the sciences at large (Kuhn, 1962) - a phase transition at the scale of theory development rather than child development. The new phase, while still consolidating, has already been dubbed the "science of complexity."

2. What phenomena should be studied? Theorists who have embraced the DS approach claim that it throws badly needed light on developmental phenomena. Yet there is widespread disagreement as to the phenomena thus illuminated. For European developmentalists van der Maas and van Geert, Piagetian stages are of primary interest. However, North American developmentalists Smith and Thelen (1994) dismiss general stages and examine the development of concepts and skills instead. Both of these camps restrict themselves to normative development, whereas Fogel (1993) and Lewis (1995) take the individual personality or relationship as the unit of analysis. Most theoretical approaches have a focus of convenience, a range of phenomena for which they provide useful insights and heuristics. How can the DS approach have such a focus and still encompass so much?

DS approaches specify an outlook on how development works, not a particular set of phenomena to study (van Geert, 1998). In fact, the generality of DS principles makes them easy to apply to almost any developmental phenomenon. A DS lens can also analyze phenomena at any scale and link these phenomena within a single macroscopic model. For example, the debate about general stages versus independent skills is an old one, but it can finally be codified and resolved by applying the DS construct of phase transitions across time scales. DS principles can accommodate both individual and normative profiles as well, because the flexibility of system definition permits the analysis of phenomena of any order. It is this very breadth of applicability that encourages the hope for an integrated account of development built on DS foundations, an account that coordinates a wide range of phenomena with a common set of principles.

3. What is the medium of development? DS models also differ as to the medium in which development takes place. Self-organization has been proposed in the brain (Freeman, 1995; Schore, in press), the body (Thelen \& Ulrich, 1991), the psychological system (Lewis, 1995), and the family (Fogel, 1993). But it seems unlikely that a single framework could have real explanatory power across these different substrates. Synapses and siblings simply do not work the same 
way. An even more difficult problem is that knowledge of complex dynamic systems derives from the study of physical matter (and energy) in the natural sciences. Indeed, DS developmentalists have analyzed muscular data and neurophysiological data with clear success (Newell \& Molenaar, 1998). But most developmental research falls between the muscles and the brain. Can the psychological system be said to self-organize, literally, as well? Can a framework invented for the study of matter be borrowed for the study of mind?

Some variant of this question has challenged the scientific study of psychology since its inception. Must we stick to physical descriptions to invoke scientific explanations? In fact, explanations can be independent of the mechanisms that instantiate them (Brown, 1994). Brown points to Darwin's natural selection as an explanation that supersedes any particular domain (cf. Edelman, 1987). Indeed, physical principles such as energy, equilibrium, stress, and resiliency and biological principles such as selection and adaptation have been enormously relevant to psychologists, and to developmental psychologists in particular (Valsiner, 1995). Self-organization also appears well tailored to describe the emergence of psychological forms, which are macroscopic and highly ordered and which both emerge from and constrain interactions among their constituents. Self-organization has already been persuasively modeled in nonphysical systems including neural networks, stock markets, and social organizations. If it can be modeled in psychological systems as well, the integration of physical and mental levels of description may be closer than ever before.

4. What is the method of investigation? Dynamic systems theory is a mathematical theory, and developmentalists such as van der Maas and van Geert insist on a mathematical approach. They criticize Thelen and Smith for their "metaphorical" use of DS constructs (van der Maas, 1995; van Geert, 1996). Yet their own math models describe highly general phenomena that could be plucked out of any data set. Meanwhile, Thelen, Smith, and Fogel have captured the attention of many developmentalists by palpably demonstrating self-organization through descriptive analyses of infant-mother relationships (Fogel, 1993) and abilities such as walking and searching (Thelen \& Smith, 1994). Still, description is not enough for modeling, and the statistical methods used by these investigators do not measure DS features per se. It is still unclear what methods are useful and appropriate for DS research.

Evolutionary biologists measure changes in beak sizes in the wild, study DNA sequences in the lab, and glue fossil fragments together on the workbench. But it is this very combination of disparate methods that has led to rapid progress. Different DS methods in developmental psychology may also play complementary roles, assembling different pieces of the same puzzle. Moreover, we are just beginning to glimpse what a general model of developmental self-organization might look like. This is a period of theoretical reorientation that demands new methods and new combinations of methods. Examples may include simulations, cellular automata, new graphical depictions, and new combinations of conventional statistics and mathematical or descriptive techniques (Lewis, Lamey, \& Douglas, 1999). Methodologies undergo their own upheavals during theoretical transitions, and it is too early to tell what will ultimately prove most useful.

5. What is the objective? Does the DS approach favor one theory of development, many theories, or none at all? Thelen and Smith (1994) propose a comprehensive DS theory of development, integrating Edelman's (1987) neural selection ideas with their own findings on cognitive and motor processes. Van Geert (1996) and van der Maas (1995) see the DS approach as a means for analyzing the lawfulness of developmental profiles, not to build new theories but to improve on existing theories such as that of Piaget. For Fogel (1993), DS thinking is an alternative to conventional psychological reductionism, and its role is to generate insights that will contribute to varied theoretical efforts. Lewis (1995) and Schore (in press) have built new psychological and neurobiological models on principles of self-organization, with an eye to constructing theories of their own.

These assorted agendas suggest a good deal of disparity in the DS camp, but it is not the sort of fragmentation that characterizes developmental psychology at large. Instead, DS workers have discovered a new conceptual toolkit, and they are applying it to different projects at different scales and different stages of completion. Moreover, these projects may turn out to be aspects of a single theoretical effort in the long run. Psychological and neurobiological models, Piagetian insights, and fine-grained developmental profiles can be calibrated and coupled with precision because they share the same underlying conceptual terms. Whether DS approaches eventually converge on a single theory of development or a number of different theories, they now provide a unified explanatory space for explorations in many directions.

Looking at development as self-organization does not specify a particular phenomenon or a particular medium. It does not constrict methodological choices and it does not even demand a uniform vocabulary. 
Self-organization is not a single theory or model. Rather, it is an idea, like Darwin's "dangerous" one (Dennett, 1996; see Kauffman, 1995), that promises coherent explanation in the study of pattern, change, and novelty. This idea has emerged across many scientific disciplines in the last few years, and it is not surprising that it has emerged in developmental psychology as well. What is surprising and exciting is that it provides the foundation for a general framework that can integrate our viewpoints within a larger scientific perspective. The turbulence in dynamic systems thinking is thus a creative one, characteristic of phase transitions in general, and it promises to resolve to a coherent account of the developmental process itself.

\section{ACKNOWLEDGMENT}

This work was supported by a grant from the Natural Sciences and Engineering Research Council of Canada.

\section{ADDRESS AND AFFILIATION}

Corresponding author: Marc D. Lewis, University of Toronto, OISE/UT, 252 Bloor Street West, Toronto, ON M5S 1V6, Canada; e-mail: mlewis@oise.utoronto.ca.

\section{REFERENCES}

Abraham, F. D., \& Gilgen, A. R. (1995). Chaos theory in psychology. Westport, CT: Praeger.

Brown, T. (1994). Affective dimensions of meaning. In W. F. Overton \& D. S. Palermo (Eds.), The nature and ontogenesis of meaning (pp. 167-190). Hillsdale, NJ: Erlbaum.

Capra, F. (1996). The web of life. New York: Bantam.

Case, R. (1985). Intellectual development: Birth to adulthood. New York: Academic Press.

Case, R., Okamoto, Y., Griffin, S., McKeough, A., Bleiker, C., Henderson, B., \& Stephenson, K. M. (1996). The role of central conceptual structures in the development of children's thought. Monographs of the Society for Research in Child Development, 246(61, Serial No. 246).

Chapman, M. (1991). Self-organization as developmental process: Beyond the organismic and mechanistic models? In P. Van Geert \& L. P. Mos (Eds.), Annals of theoretical psychology (Vol. 7, pp. 335-348). New York: Plenum.

Dennett, D. C. (1996). Darwin's dangerous idea: Evolution and the meanings of life. New York: Touchstone/Simon \& Schuster.

Derryberry, D., \& Rothbart, M. K. (1997). Reactive and effortful processes in the organization of temperament. Development and Psychopathology, 9, 633-652.

Edelman, G. M. (1987). Neural Darwinism. New York: Basic Books.

Elman, J. L., Bates, E. A., Johnson, M. H., Karmiloff-Smith, A., Parisi, D., \& Plunkett, K. (1996). Rethinking innateness:
A connectionist perspective on development. Cambridge, MA: MIT Press.

Fischer, K. W. (1980). A theory of cognitive development: The control and construction of hierarchies of skills. Psychological Review, 87, 477-531.

Fogel, A. (1993). Developing through relationships: Origins of communication, self, and culture. Chicago: University of Chicago Press.

Freeman, W. J. (1995). Societies of brains. Hillsdale, NJ: Erlbaum.

Haken, H. (1987). Synergetics: An approach to self-organization. In F. E. Yates (Ed.), Self-organizing systems: The emergence of order. New York: Plenum.

Izard, C. E., Ackerman, B., Schoff, K., \& Fine, S. (in press). In M. D. Lewis \& I. Granic (Eds.), Emotion, development, and self-organization: Dynamic systems approaches to emotional development. New York: Cambridge University Press.

Karmiloff-Smith, A. (1992). Beyond modularity: A developmental perspective on cognitive science. Cambridge, MA: Bradford/MIT Press.

Kauffman, S. (1995). At home in the universe: The search for the laws of self-organization and complexity. New York: Oxford University Press.

Keating, D. P. (1990). Charting pathways to the development of expertise. Educational Psychologist, 25, 243-267.

Kelso, J. A. S. (1995). Dynamic patterns: The self-organization of brain and behavior. Cambridge, MA: Bradford/MIT Press.

Kuhn, T. S. (1962). The structure of scientific revolutions. Chicago: University of Chicago Press.

Lerner, R. M. (1995). Developing individuals within changing contexts: Implications of developmental contextualism for human development research, policy, and programs. In T. A. Kindermann \& J. Valsiner (Eds.), Development of person-context relations (pp. 13-37). Hillsdale, NJ: Erlbaum.

Lewis, M. (1997). Altering fate: Why the past does not predict the future. New York: Guilford.

Lewis, M. D. (1995). Cognition-emotion feedback and the self-organization of developmental paths. Human Development, 38, 71-102.

Lewis, M. D., \& Douglas, L. (1998). A dynamic systems approach to cognition-emotion interactions in development. In M. F. Mascolo \& S. Griffin (Eds.), What develops in emotional development? (pp. 159-188). New York: Plenum.

Lewis, M. D., \& Granic, I. (1999). Who put the self in selforganization? A clarification of terms and concepts for developmental psychopathology. Development and Psychopathology, 11, 365-374.

Lewis, M. D., Lamey, A. V., \& Douglas, L. (1999). A new dynamic systems method for the analysis of early socioemotional development. Developmental Science, 2, 457475.

Magai, C., \& Nusbaum, B. (1996). Personality change in adulthood: Dynamic systems, emotions, and the transformed self. In C. Magai \& S. H. McFadden (Eds.), Handbook of emotion, adult development, and aging (pp. 403420). San Diego: Academic Press.

Molenaar, P. C. M. (1986). On the impossibility of acquiring more powerful structures: A neglected alternative. $\mathrm{Hu}$ man Development, 29, 245-251.

Newell, K. M., \& Molenaar, P. C. M. (1998). Applications of 
nonlinear dynamics to developmental process modeling. Mahwah, NJ: Erlbaum.

Overton, W. F. (1984). World views and their influence on psychological theory and research: Kuhn-Lakatos-Laudan. In H. W. Reese (Eds.), Advances in child development and behavior (Vol. 18, pp. 191-226). New York: Academic Press.

Pascual-Leone, J., \& Goodman, D. (1979). Intelligence and experience: A neo-Piagetian approach. Instructional Science, 8, 301-367.

Prigogine, I., \& Stengers, I. (1984). Order out of chaos. New York: Bantam.

Rose, S. P., \& Fischer, K. W. (1998). Models and rulers in dynamical development. British Journal of Developmental Psychology, 16, 123-131.

Ryan, R. M., Kuhl, J., \& Deci, E. L. (1997). Nature and autonomy: An organizational view of social and neurobiological aspects of self-regulation in behavior and development. Development and Psychopathology, 9, 701728.

Sameroff, A. J. (1995). General systems theories and developmental psychopathology. In D. Cicchetti \& D. J. Cohen (Eds.), Developmental psychopathology (Vol. 1, pp. 659695). New York: Wiley.

Schore, A. N. (in press). The self-organization of the right brain and the neurobiology of emotional development. In M. D. Lewis \& I. Granic (Eds.), Emotion, development, and self-organization: Dynamic systems approaches to emotional development. New York: Cambridge University Press.

Shultz, T. R. (1998). A computational analysis of conservation. Developmental Science, 1, 103-126.

Siegler, R. S., \& Jenkins, E. (1989). How children discover new strategies. Hillsdale, NJ: Erlbaum.

Smith, L. B. (1995). Self-organizing processes in learning to learn words: Development is not induction. In C. A. Nelson (Ed.), New perspectives on learning and development:
Minnesota Symposia on Child Psychology (Vol. 28, pp. 132). New York: Academic Press.

Sroufe, L. A. (1995). Emotional development: The organization of emotional life in the early years. New York: Cambridge University Press.

Thelen, E., \& Smith, L. B. (1994). A dynamic systems approach to the development of cognition and action. Cambridge, MA: Bradford/MIT Press.

Thelen, E., \& Ulrich, B. D. (1991). Hidden skills: A dynamic systems analysis of treadmill stepping during the first year. Monographs of the Society for Research in Child Development, 56(1, Serial No. 223).

Valsiner, J. (1995). Processes of development, and search for their logic: An introduction to Herbst's co-genetic logic. In T. A. Kindermann \& J. Valsiner (Eds.), Development of person-context relations (pp. 55-65). Hillsdale, NJ: Erlbaum.

van der Maas, H. L. J. (1995). Beyond the metaphor? Cognitive Development, 10, 621-642.

van der Maas, H. L. J., \& Molenaar, P. C. M. (1992). Stagewise cognitive development: An application of catastrophe theory. Psychological Review, 99, 395-417.

van Geert, P. (1994). Dynamic systems of development: Change between complexity and chaos. New York: Prentice Hall/ Harvester Wheatsheaf.

van Geert, P. (1996). The dynamics of Father Brown: Essay review of A dynamic systems approach to the development of cognition and action by E. Thelen and L. B. Smith. Human Development, 39, 57-66.

van Geert, P. (1998). We almost had a great future behind us: The contribution of non-linear dynamics to developmental-science-in-the-making. Developmental Science, 1, 143-159.

Varela, F. J., Thompson, E., \& Rosch, E. (1991). The embodied mind: Cognitive science and human experience. Cambridge, MA: MIT Press. 